\title{
Палладистое золото (Au, Pd) в золото-сурымяных рудах Удерейского месторождения, Енисейский кряж
}

Рудашевский Н.С. ${ }^{1}$, Горбунов А.А. ${ }^{1,2}$, Антонов А.В. ${ }^{3}$, Аликин О.В. ${ }^{1,2}$, Рудашевский В.Н. ${ }^{1}$, Боброва О.В. ${ }^{4}$

${ }^{1}$ ООО «ЦНТ Инструментс», Санкт-Петербург

${ }^{2}$ Санкт-Петербургский Горный университет, art.gor.psu@ya.ru

${ }^{3}$ Всероссийский научно-исследовательский геологический институт им. А. П. Карпинского, СанктПетербург

${ }^{4} О О О$ «Коралайна Инжиниринг», Москва

Аннотация. Изучена золото-сурьмяная минерализация поступающей на обогащение руды Удерейского месторождения. В «тяжелых» концентратах гидросепарации первичной руды обнаружены зерна самородного золота (Au, $\mathrm{Ag})$, содержащие участки более позднего палладистого золота (Au, $\mathrm{Pd}): 3.3-7.9$ масс. \% Pd, - первая находка такого соединения в $\mathrm{Au}-\mathrm{Sb}$ типе оруденения. Наличие палладия (палладистого золота) - прямые геохимические и минералогические доказательства источника $\mathrm{Au}-\mathrm{Sb}$ минерализации, связанного, помимо с гранитоидным, еще и с базитовым магматизмом.

Ключевые слова: палладистое самородное золото, золото-сурьмяные руды, генезис Au-Sb минерализации, 3D-минералогическая технология исследования.

\section{The palladium gold (Au, Pd) from Au-Sb ores of the Uderejskoe deposit, Enisejskij upland}

\author{
Rudashevsky N.S. ${ }^{1}$, Gorbunov A.A. ${ }^{1,2}$, Antonov A.V. ${ }^{3}$, Alikin O.V. ${ }^{1,2}$, Rudashevsky V.N. ${ }^{1}$, \\ Bobrova O.V. ${ }^{4}$ \\ ${ }^{1}$ CNT Instruments, Saint Petersburg \\ ${ }^{2}$ Saint Petersburg Mining University, art.gor.psu@ya.ru \\ ${ }^{3}$ A.P. Karpinsky Russian Geological Research Institute, Saint Petersburg \\ ${ }^{4}$ Coralina Engineering, Moscow
}

Abstract. Au-Sb mineralization of the Uderejskoe deposit ore has been studied. Grains of native gold (Au, Ag) has been found in the concentrates of «heavy» minerals. The native gold ( $\mathrm{Au}, \mathrm{Ag})$ grains contain the more recent sites of palladium gold $(\mathrm{Au}, \mathrm{Pd}): \mathrm{Pd}=3.3-7.9 \mathrm{wt} . \%$. It is the first finding of palladium gold within the Au-Sb ore type. The presence of palladium gold in ores is mineralogical and geochemical evidence of two types of mineralization sources - both granite and mafic intrusions.

Key words: palladium native gold, gold-antimony ores, the genesis of the Au-Sb mineralization, 3D-mineralogical technology of study.

Удерейское золото-сурьмяное месторождение расположено на юге заангарской части Енисейского кряжа и приурочено к восточному крылу Татарской антиклинали. Оруденение контролируется зоной Ишимбинского глубинного разлома (Дистанов и др., 1977; Сазонов и др., 2010).

Золоторудная минерализация Удерейского месторождения на сегодня остается слабо изученной. В ряде публикаций (Дистанов и др., 1977; Сазонов и др., 1990; Власов и др., 2011; Бутько, 2016 и др.) указывается лишь, что самородное золото в рудах - тонкодисперсное, образует мелкие (4-5 мкм) включения в арсенопирите, стибните и на границах этих сульфидов с кварцем. Отмечается, что содержание золота напрямую коррелирует с количеством арсенопирита в рудах, для стибнита такая зависимость не обнаруживается.

Нами изучена представительная проба поступающей на обогащение руды Удерейского месторождения. Исследования руды проведены по оригинальной 3D-минералогической технологии, включающей «бережное» (стадиальное кратковременное) дробление первичного материала, мокрый рассев на узкие классы крупности, гравитационное обогащение узких размерных фракций 
запатентованным методом гидросепарации (HS-концентраты) и изготовление однослойных полированных шлифов из HS-концентратов (Рудашевский и др., 2001, 2017, 2018; Rudashevsky et al., 2001; Рудашевский, Рудашевский, 2006, 2007, 2017; Cabri et al., 2006; 2008; Oberthür et al., 2008). Определен химический состав первичной руды и продукта её обогащения. Полированные шлифы HS-концентратов изучены микрозондовым методом (Camscan 2500 с полупроводниковым детектором Pentafet, ВСЕГЕИ).

В полированных шлифах HS-концентратов удерейской руды на микрозонде диагностировано палладистое золото (Au, Pd) - впервые для золото-сурьмяного типа оруденения. Это редкое соединение (Au, Pd) установлено в Бразилии под названием «порпецит», но название не было утверждено КНМ ММА, поскольку минерал является структурным аналогом и разновидностью по химическому составу самородного золота (www.mindat.org).

Концентраты гидросепарации удерейской руды представлены тремя главными сульфидами: арсенопиритом, пиритом и стибнитом. Встречены также единичные зерна цинкенита $\mathrm{Pb}_{9} \mathrm{Sb}_{22} \mathrm{~S}_{42}$. халькостибита $\mathrm{CuSbS}_{3}$, ульманнита $\mathrm{NiSbS}$, галенита $\mathrm{PbS}$, сфалерита ZnS и киновари $\mathrm{HgS}$.

В мелких фракциях «тяжелых» концентратов (71-45 мкм и < 45 мкм) определены следующие минералы золота: самородное золото - твердый раствор ( $\mathrm{Au}, \mathrm{Ag}$ ), самородное палладистое золото $(\mathrm{Au}, \mathrm{Pd})$, самородное сурьмянистое золото $(\mathrm{Au}, \mathrm{Sb})$, ауростибит $\mathrm{AuSb}_{2}$ и практически чистое самородное золото Аu.

Самородное золото (Au, $\mathrm{Ag}$ ) - свободные зерна в продукте дробления руды размерами 30-70 мкм, имеет широкий интервал составов: 2.1-24.2 масс. \% Ag. Вариации концентрации Аg определяются как в различных индивидах, так и в пределах одного зерна. Высокопробные участки тяготеют к краям зерен и содержат реликтовые фрагменты богатых Ag первичных составов. Зерна самородного золота (Au, Ag) содержат включения пирита и стибнита. Ауростибит $\mathrm{AuSb}_{2}$ обрастает тонкими каймами практически чистого самородного золота и сурьмянистого золота (Au, $\mathrm{Sb})$, содержащего 3-6 масс. \% Sb. В арсенопирите (реже в пирите и стибните), кроме того, обнаружены многочисленные тонкие (доли микрометра - 10 мкм) неправильной формы включения практически чистого самородного золота.

В составе нескольких «крупных» зерен самородного золота (Au, Ag) на микрозонде нами диагностированы участки палладистого золота. Новообразования (Au, Pd), приурочены к краям зерна-
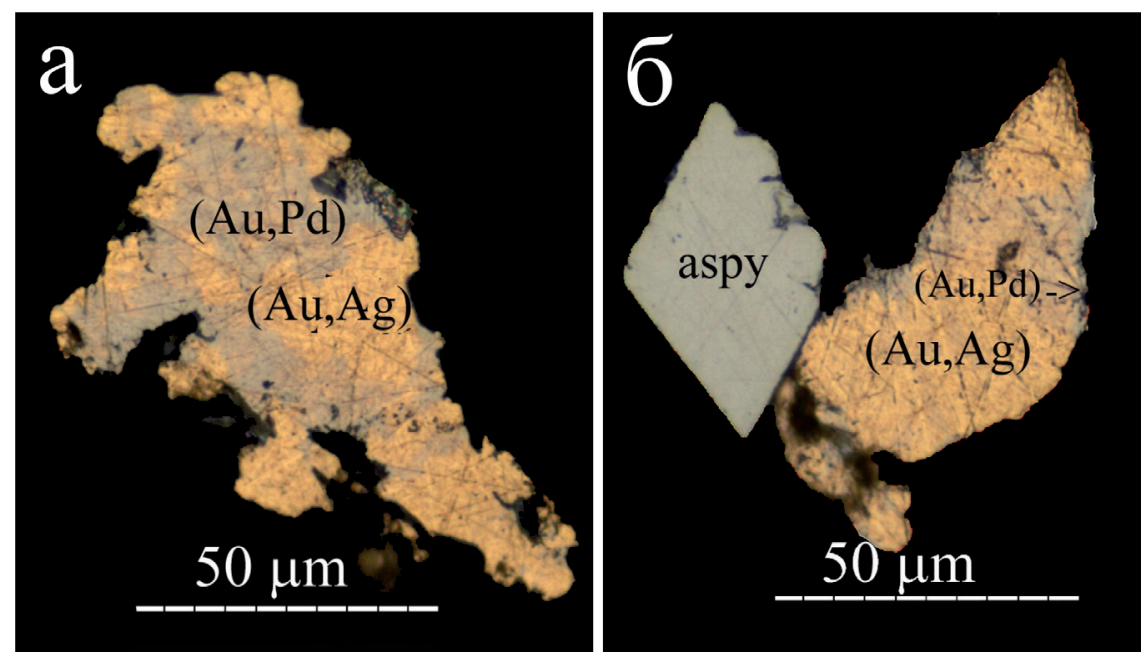

Рис. 1. Свободные зерна самородного золота (Au, $\mathrm{Ag}$ ) с участками палладистого золота (Au, Рd); полированный шлиф HS-концентрата руды, фракция 45-71 мкм; фото в отраженном свете (стереомикроскоп MZ6, камеры Leica DC 300, программный пакет Autopano Giga, ВСЕГЕИ); аspy - арсенопирит.

Fig 1. The recovered grains of native gold ( $\mathrm{Au}, \mathrm{Ag})$ containing sites of palladium gold (Au, Pd). Polished mount of HS-concentrate $(45-71 \mu \mathrm{m})$. Optical image (reflected light). MZ6 stereomicroscopy, Leica DC 300 camera, Autopano Giga software, Karpinsky Institute. Aspy - arsenopyrite. 


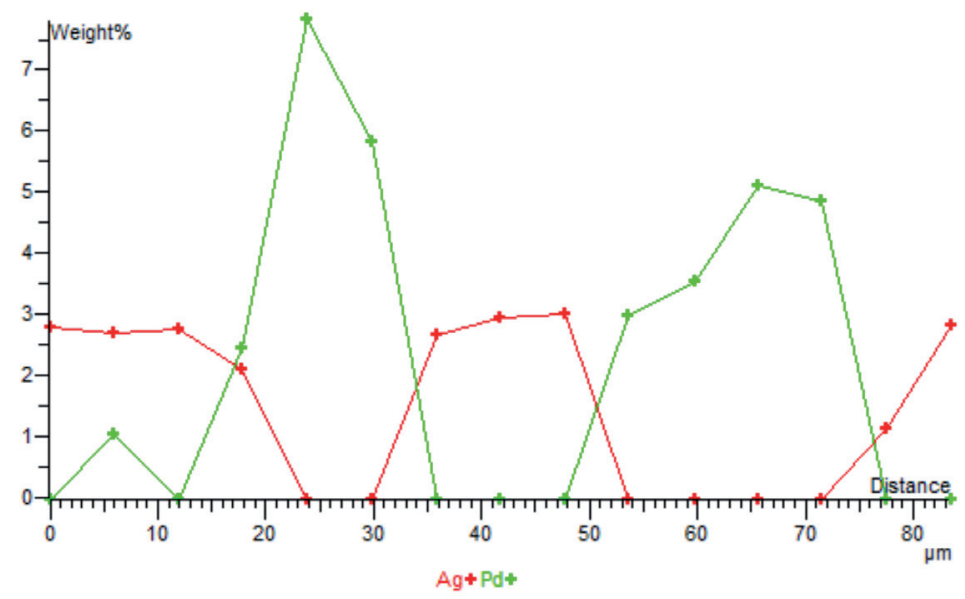

Рис. 2. Концентрационные кривые $\mathrm{Ag}$ и Рd по профилю через середину зерна (Au, $\mathrm{Ag})+(\mathrm{Au}, \mathrm{Pd})$ - см. pис. 1, a.

Fig. 2. The concentration curves of $\mathrm{Ag}$ and $\mathrm{Pd}$ along the profile through the middle of the grain $(\mathrm{Au}, \mathrm{Ag})+(\mathrm{Au}, \mathrm{Pd})-\mathrm{see}$ Fig. 1, a.

матрицы и проникают в него, замещая первичное самородное золото (Au, $\mathrm{Ag}$ ) - (рис. 1). В составе палладистого золота (3.3-7.9 масс. \% Pd) серебро практически отсутствует, в реликтовых участках самородного золота концентрации серебра невысокие (2.3-2.6 масс. \%) - табл. 1, рис. 2.

Таблица 1. Химический состав (масс. \%) зерен самородного золота (Au, $\mathrm{Ag})$, содержащего участки палладистого золота (Au, Pd).

Table 1. Chemical composition (wt. \%) of native gold grains ( $\mathrm{Au}, \mathrm{Ag}$ ) and palladium gold sites (Au, Pd).

\begin{tabular}{|c|l|c|c|c|c|}
\hline Анализ & \multicolumn{1}{|c|}{ Рисунок } & Разновидность & $\mathrm{Au}$ & $\mathrm{Ag}$ & $\mathrm{Pd}$ \\
\hline 1 & 1, a среднее, $\mathrm{n}=7$ & $(\mathrm{Au}, \mathrm{Ag})$ & 97.4 & 2.6 & Не обн. \\
\hline 2 & 1, а, макс $\mathrm{Pd}$ & $(\mathrm{Au}, \mathrm{Pd})$ & 92.1 & не обн. & 7.9 \\
\hline 3 & 1, б, среднее, $\mathrm{n}=5$ & $(\mathrm{Au}, \mathrm{Ag})$ & 97.7 & 2.3 & не обн. \\
\hline 4 & 1, б, макс $\mathrm{Pd}$ & $(\mathrm{Au}, \mathrm{Pd})$ & 96.7 & не обн. & 3.3 \\
\hline
\end{tabular}

Примечание. $\mathrm{n}$ - количество анализов; макс $\mathrm{Pd}$ - анализ с максимальным содержание Рd; условия анализов: микрозонд Camscan 2500 с полупроводниковым детектором Pentafet, 20 kV, 20 nA, диаметр зонда 1 мкм, стандарты - чистые металлы.

С учетом новых минералогических данных в рудных продуктах определены содержания $\mathrm{Au}$ и $\mathrm{Pd}$ (табл. 2). Pd установлен в заметных количествах в первичной руде (ан. $1-0.023$ г/т), накапливается в тонкой фракции руды (ан. $2-0.483$ г/т) и концентрируется гравитационным обогащением (гидросепаратор HS-11) в этом продукте (ан. 3 - 0.977 г/т).

Таблица 2. Распределение зотота и палладия (г/т) в изученных рудных продуктах.

Table 2. Distribution of Au and Pd (g/t) within the studied ore products.

\begin{tabular}{|l|c|c|}
\hline \multicolumn{1}{|c|}{ Объект } & $\mathrm{Au}$ & $\mathrm{Pd}$ \\
\hline 1. Руда (первичный материал, продукт крупностью <500 мкм) & 1.503 & 0.023 \\
\hline 2. Руда первичная, класс крупности 10-45 мкм & 1.339 & 0.483 \\
\hline 3. Руда после обогащения, класс крупности 10-45 мкм & 7.511 & 0.977 \\
\hline
\end{tabular}

Примечание. Химическая лаборатория ALS Group (Москва), пробирный анализ.

Золоторудную минерализацию в регионе обычно связывают с гранитоидным либо с основным магматизмом (Петровская, 1973; Новгородова, 1983; Некрасов, 1981; Сазонов и др., 1990; Спиридонов, 2010). Абсолютный возраст сурьмяной и золото-сурьмяной минерализации Енисейского Кряжа лежит в интервале 677-605 млн. лет (Власов, 1985; Сазонов и др., 1990; Неволько, 2009). В заангарской части Енисейского кряжа магматические породы представлены от ультрамафитов до кислых, включая их щелочные разновидности. Преобладающим развитием пользуются разновозраст- 
ные гранитоиды (возраст в интервале 1000-625 млн. лет). Гранитоиды занимают около 10 \% территории, на долю других магматических пород приходится около $0.1 \%$ площади региона (Сазонов и др., 2010). Вместе с тем, П.А Неволько и А.С Борисенко (2009) полагают, что временные интервалы формирования сурьмяной и золотой минерализации на Енисейском кряже не совпадают с основными этапами развития гранитоидного магматизма, а в большей мере коррелируют с периодами проявления щелочных и щелочно-базитовых дайковых комплексов.

Новые минералогические данные выявили, по крайней мере, два этапа формирования золоторудной минерализации на Удерейском месторождении: 1) образование первичного традиционного самородного золота I (Au, Ag), 2) формирование более позднего (замещающее самородное золото I) высокопробного (до $100 \% \mathrm{Au}$ ) золота + палладистое самородное золото ( $\mathrm{Au}, \mathrm{Pd})+$ ауростибит $\mathrm{AuSb}_{2}+$ сурьмянистое самородное золото (Au, $\left.\mathrm{Sb}\right)$. Второй этап, видимо, связан с наложением сурьмяной минерализации на первичную золото-сульфидную. При этом происходила ремобилизация и перекристаллизация самородного золота - формирование новых его генераций: вынос серебра $\rightarrow$ чистое самородное золото, привнос сурьмы $\rightarrow$ ауростибит и сурьмянистое самородное золото, привнос палладия $\rightarrow$ палладистое золото. Особенности химического состава новых генераций минералов золота и сопровождающих их сульфидов (стибнит, цинкенит, халькостибит, ульманнит) являются прямыми геохимическими и минералогическими доказательства источника $\mathrm{Au}-\mathrm{Sb}$ минерализации, связанного, помимо с гранитоидным, еще и с наложенным базитовым магматизмом.

В заключение отметим, что получение надежной новой столь сложной минералогической информации для бедных тонкозернистых $\mathrm{Au}-\mathrm{Sb}$ руд является новым примером высокой чувствитель-

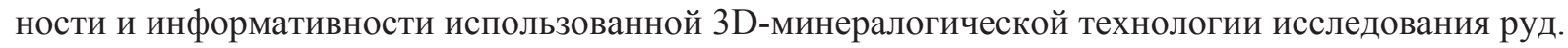

\section{Литература}

1. Буряк В.Н. Метаморфизм и рудообразование. М. Изд-во: Недра. 1982. 256 с.

2. Бутько Е.Р. Золото-арсенопирит-пиритовые руды Удерейского месторождения / Матер. Междунар. конф. студентов, аспирантов и молодых учёных «Проспект Свободный-2016» посвящённой Году образования в СНГ. Красноярск. 2016. С. 20-23.

3. Власов Е.А., Бакшеев И.А., Нагорная Е.В., Прокофьев В.Ю., Аплеталин А.В., Свинтицкий И.Л. Минеральная зональность и условия формирования $\mathrm{Au}-\mathrm{Sb}$ месторождения Удерей, Красноярский край // Матлы V Междунар. Симпозиума «Минеральное разнообразие - исследование и сохранение». София. 2011. C. 85-90.

4. Дистанов Э.Г., Оболенский А.А., Кочеткова К.В., Борисенко А.С. Удерейское сурьмяное месторождение в Енисейском кряже / Геология и генезис рудных месторождений юга Сибири (отв. ред. В.А. Кузнецов). АН СССР. Сиб. отд. Тр. ин-та геологии и геофизики. Вып. 364. Новосибирск. 1977. С. 5-32.

5. Некрасов И.Я. Геохимия, минералогия и генезис золоторудных месторождений. М.: Наука, 1991. 302 с.

6. Новгородова М.И. Самородные металлы в гидротермальных рудах. М.: Наука. 1983. 287 с.

7. Петров В.Г. Золото в опорных разрезах верхнего докембрия западной окраины Сибирской платформы / В.Г. Петров. Новосибирск: Наука. 1976. 211 с.

8. Петровская Н.В. Самородное золото (общая характеристика, типоморфизм, вопросы генезиса) М. Изд-во: Наука. 1973. 348 C.

9. Рудашевский Н.С., Лупал С.Д., Рудашевский В.Н. Гидравлический классификатор. Патент на изобретение № 216530. Российская Федерация. М. 2001.

10. Рудашевский Н.С., Рудашевский В.Н. Гидравлический классификатор. Патент на изобретение № 2281808. Российская Федерация. М. 2006.

11. Рудашевский Н.С., Рудашевский В.Н. Гидравлический классификатор. Патент на изобретение № 69418, полезная модель. Российская Федерация. М. 2007.

12. Рудашевский Н.С. Рудашевский В.Н. 3D-Минералогическая технология исследования руд и технологических продуктов коренных месторождений благородных металлов / Материалы Юбилейного съезда Российского минералогического общества «200 лет РМО». СПб. 2017. Т. 2. С. 146-148.

13. Рудашевский Н.С., Рудашевский В.Н., Антонов А.В. Универсальная минералогическая технология исследования горных пород, руд и технологических продуктов // Региональная геология и металлогения. 2018. № 73. C. $88-102$.

14. Сазонов А.М., Ананьев А.А., Власов В.С. Об условиях пространственного совмещения золоторудной и сурьмяной минерализации в сланцевых толщах одного из районов Сибири / Геологические и геохимические критерии золотого оруденения. Новосибирск: Наука. Сиб. отделение. 1990. С. 84-96. 
15. Сазонов А.М., Ананьев А.А., Полева Т.В., Хохлов А.Н., Власов В.С., Звягина Е.А., Федорова А.В., Тишин П.А., Леонтьев С.И. Золоторудная металлогения Енисейского кряжа: геолого-структурная позиция, структурные типы рудных полей // Журнал Сибирского федерального университета. Серия: техника и технологии. Изд-во: Сибирский федеральный университет. 2010. Т. 3. № 4. С. 371-395.

16. Спиридонов Э.М. Обзор минералогии золота в ведущих типах Аи минерализации // Золото Кольского полуострова и сопредельных регионов / Тр. Всеросс. (с междунар. участием) науч. конф., посвященной 80-летию Кольского научного центра РАН (Ред. Ю.Л. Войтеховский). Апатиты. 2010. С. 143-171.

17. Cabri L.J., Rudashevsky N.S., Rudashevsky V.N., Lastra R. Hydroseparation: a new development in process mineralogy of platinum-bearing ores / CIM Bull. 2006. V. 99(1092). P. 1-7.

18. Cabri L.J., Rudashevsky N.S., Rudashevsky V.N., Oberthür T. Electric-pulse disaggregation (Epd), hydroseparation (Hs) and their use in combination for mineral processing and advanced character-ization of ores / Canadian Mineral Processors 40th Annual Meeting, Ottawa, Proceedings Volume. 2008. P. 211-235.

19. Oberthür T., Melcher F., Sitnikova M., Rudashevsky N.S., Rudashevsky V.N., Cabri L.J., Lodziak J., Klosa D., Gast L. Combination of novel mineralogical methods in the study of noble metal ores - focus on pristine (Bushveld, Great Dyke) and placer platinum mineralization / Proceedings, 9th International Congress for Applied Mineralogy (ICAM), Brisbane, QLD. 2008. P. 187-194.

20. Rudashevsky N.S., Rudashevsky V.N., Lupal S.D., Method for separating granular materials and device for carrying out said method / Patent Cooperation Treaty PCT/RU01/00123, Moscow, 20 April 2001, 10 May 2001. (Russian and English text). 